\title{
RUUT VEENHOVEN
}

\section{WORLD DATABASE OF HAPPINESS}

(Accepted 7 May, 1994)

\begin{abstract}
The World Database of Happiness is an ongoing register of research on subjective appreciation of life. Its purpose is to make the wealth of scattered findings accessible, and to create a basis for further meta-analytic studies. The database involves four sections:
\end{abstract}

1. Bibliography of Happiness. Presents all contemporary scientific publications. Detailed subject classification. Current content: 2472 titles, mainly in English.

2. Catalogue of Happiness Correlates. Presents mini-abstracts of correlational research findings. Restricts to selected indicators of happiness. Detailed subject classification. Current content: 6098 findings from 512 studies in 45 nations between 1911-1993.

3. Catalogue of Happiness in Nations. Presents responses on selected survey questions in nation samples. Current content: 689 surveys in 56 nations 1946-1993.

4. Directory of Investigators. Addresses of most authors on the subject.

The World Database of Happiness is available in books and on computer files. Computer files are free available through Intemet on the anonymous ftp-server of Erasmus University Rotterdam Netherlands. Ftp-address: ftp.eur.nl (pub/database.happiness).

\section{INTRODUCTION}

\section{Interest in happiness}

Happiness is highly valued matter. Most people agree that it is better to enjoy life than to suffer, and endorse public policies that aim at creating greater happiness for a greater number of people. Though not everybody accepts the utilitarian axiom that happiness is ultimately the only value, the desirability of happiness as such as almost undisputed. This appears in high ranks for happiness in survey studies about value priorities (Harding, 1985). 
The aim of creating greater happiness for a greater number requires understanding of happiness. First of all it demands that we can grasp the main determinants of happiness; not only what makes people happy, but also the reason why. Secondly, we also must have a view on consequences of happiness, in order to detect possible self-destructive effects and to appraise synergy with other values.

Efforts to understand human happiness have absorbed a lot of thought. Happiness was a major issue in early Greek philosophy and several later philosophical schools. Currently the subject gains attention in the social sciences, in particular in Social Indicators Research. Papers on happiness fill many bookshelves.

\section{Empirical study of happiness}

Philosophical speculations about happiness produced a lot of ideas, but little operational knowledge. In fact, it raised more questions than answers. Many theoretical controversies could not be solved by the logic of reasoning alone; usually, empirical validation was not possible.

The advent of the social sciences promised a breakthrough. New methods for empirical research opened the possibility to test theories of happiness and to identify conditions for happiness inductively. This instigated a lot of research. In the last decades some 3000 empirical studies have considered the matter; in the beginning mainly as a sideissue in studies about health and ageing, but currently also as a main subject.

This stream of research has not yet crystallized into a sound body of knowledge on happiness. Preliminary questions about conceptualization and measurement are now fairly well solved, but the understanding of processes and conditions involved in determinants and consequences of happiness is still very incomplete and tentative. There are several reasons why the new stream of empirical research on happiness has not yet brought the expected break-through. In addition to complexities in the subject matter, there are several practical problems. 


\section{Practical impediments}

The first and most simple reason for the lack of progress is lack of coordination. The research effort is highly redundant; the same issues are investigated over and over again, in the same way. As a result, the range of variables considered is still rather small and the methodological progress slow.

A related problem is that the research findings are very scattered. Most observations are in fact irretrievably bibliographical. Consequently, many of the unconventional findings get lost.

The second reason is the confusion of tongues. Words like happiness and life-satisfaction denote different phenomena. Currently most investigators define it as subjective appreciation of life-as-a-whole. However, some authors also include objective notions of mental health and appropriate behavior. Consequently, indicators of happiness used in empirical research tend to be different and often incomparable. Getting an overview of the research findings requires first of all a grouping studies that measured the same matter.

A more basic reason is in the dominant research approach. The bulk of empirical happiness studies consists of cross-sections in a particular country. Typically, investigators try to identify conditions for happiness by their correlates. For instance, the observation in American studies that the happy tend to have high incomes is seen to mean that money buys happiness and that the basic underlying mental process is social comparison. This approach falls short for several reasons.

Firstly, correlations say little about cause and effect. If rich Americans tend to more happy this does not prove that money buys happiness, because happiness can also boost earning chances. There are in fact strong indications that a positive appreciation of life facilities social functioning (Veenhoven 1989). Separation of cause and effect requires panel studies. Such studies are scarce as yet, and the data that is available is again, scattered.

Secondly, conditions for happiness are probably not the same at all times and at all places. Neither are its consequences. Though there are obviously several universal requirements for a happy life (such as 
food and possibly meaning), most effects seem to be contingent on characteristics of the person and situation. For instance, the correlation between happiness and income may be restricted to materialistic persons in socially unequal countries. Usually, such contingencies can not be detected in single studies in one country. They can be identified only if many studies are compared in a systematic meta-analysis.

Last, current correlational studies in one nation cannot grasp macrosocial conditions for happiness. The focus in on differences in happiness within nations; they are blind for variation in happiness between nations. Therefore, happiness research has as yet little relevance for major political discussions such as the priority of continuous economic growth or the benefits of human rights protection. Investigation of such matters requires cross-national studies, preferably in a semi-longitudinal design. Such studies are scarce as yet, but we can do a lot by comparing the available one-nation studies.

\section{Aims of database}

The World Database of Happiness is meant to overcome these problems.

First of all its Bibliography of Happiness provides a fairly complete inventory of contemporary publications. This may help to get an overview of the field and to trace literature on specific issues. I hope this will reduce redundance somewhat.

Secondly, the database provides two homogenous selections of research findings; a selection of correlational findings in the "Catalogue of Happiness Correlates', and a selection of distributional findings in the 'Catalogue of Happiness in Nations'. Both selections are based on the same concept of happiness and consequently on the same array of happiness indicators. Happiness is defined as 'the degree to which an individual judges the overall quality of his life-as-a-whole positively', in short: how well one likes the life one lives. This concept is delineated in more detail in Veenhoven 1984a (chapter 2). Chapter 4 of that book enumerates criteria used for selecting questions that validly indicate this phenomenon.

The Catalogue of Happiness Correlates provides an assortment of comparable correlational findings that is ordered by subject matter. The 
collection provides a convenient overview of the available research and can serve as a basis for meta-analysis. Because the collection covers data from different nations and social categories, meta-analysis can reveal universal patterns as well as contingencies. An earlier version of this data-collection was published a decade ago in the 'Databook of Happiness', part III (Veenhoven, 1984b).

The Catalogue of Happiness in Nations provides a collection of comparable observations about level and dispersion of happiness in nations. First of all, the data on the average level of happiness serves to identify the macro-social factors that mark off more and less livable societies. The data is also of use for monitoring progress and decline. The data on dispersion of happiness in nations can be used in comparative studies of inequality in life chances. A decade ago a much smaller collection of nation averages was published in the above mentioned databook as well (Part IV).

The Directory of Investigators lists addresses of scientists who have published on happiness. It is meant to facilitate communication in the field.

\section{Data gathering}

The data for these collections are largely drawn from publications on happiness in books and journal articles. However, this database is not limited to findings that reached 'authorized' publications. Grey reports and mere datafiles are included as well. One reason for this strategy is that many findings that may be relevant in a meta-analysis are not published by the original investigator, because they appeared not to be relevant in the context of this report. Another reason is that the publication process involves some systematic biases, one of which is underreport of non-correlations. By deliberately including 'unpublished' data this database allows a more realistic view of conditions for happiness. Therefore, meta-analysis based on this database can yield conclusions that differ from impressions based on narrative literature surveys. 


\section{BIBLIOGRAPHY OF HAPPINESS}

Scope:

* Any research report that refers to the subjective appreciation of life-as-a-whole, even if this subject is only a side-issue.

* Not included are related fields like 'mental health', 'social adjustment', 'alientation' and satisfaction with 'domains of life'.

Coverage 1-1-1994:

* 2472 titles.

* Almost complete coverage of the social-science literature up to 1990 in English, German, and Dutch.

* Includes not only journal articles, but also books, dissertations, conference papers and unpublished research reports.

\section{Contents:}

* Title descriptions involving:

* Author, title, publisher or journal, year of publication

* Language of the report

* Type of study

* Subject classification (388 subject categories)

* Data classification (empirical studies only)

* Time frame: past / present / future / perceived change

* Variant measured: overall happiness / hedonic level / contentment

* Included or not in 'Catalogue of Happiness Correlates' or 'Catalogue of Happiness in Nation' (depending on validity of happiness indicator)

Availability: ${ }^{2}$

* Available as a book: 'Bibliography of Happiness', RISBO, Series: Studies in Social and Cultural Transformation nr. 1, 1993, Erasmus 
University Rotterdam, Netherlands, 363 pages, ISBN 90-7259745-1.

* Available on computer file: either by E-mail or on floppy disk. The computer-file is also free available on Erasmus University's anonymous FTP-server. FTP-address: ftp.eur.n directory: pub/database.happiness filename: biblio.zip Instructions for downloading: see appendix.

CATALOGUE OF HAPPINESS CORRELATES

Scope:

* Empirical research findings on co-variants of happiness. Not only factors found to be statistically associated to happiness, but also non-correlates.

* Only findings yielded by indicators that validly tap happiness in the sense of the individuals "overall appreciation of his own lifeas-a-whole'.

* All findings that could be traced. Not only the ones that reached scientific journals.

Coverage at 1-1-1994:

* 512 Studies in 45 nations between 1911 and 1993.

* 6098 correlational findings.

* Almost complete coverage of studies that reached the International Abstracts. Incomplete but considerable coverage of findings published in books and grey reports.

\section{Contents:}

* Focused excerpts of empirical studies involving one or more acceptable happiness measures (512). These excerpts inform about:

* Bibliographic source: author, title, book or journal, year 
* Study design: data gathering, sampling

* Happiness indicator: full description

* Mini abstracts of correlational research findings (6098) ordered by subject, country and time. The abstracts include detail about:

* Bibliographic source: author, year, page reference

* Study design: population, sample, number of subjects, year

* Co-variate: label, measurement, subject-category.

* Happiness indicator: type

* Statistics: association, significance, elaboration

\section{Availability: ${ }^{2}$}

* The mini abstracts of findings are published in a reference book entitled 'Correlates of Happiness', \pm 1000 pages. ISBN 90-7259747-8. Published by RISBO, Series Studies in Social and Cultural Transformation nr. 3, Erasmus University Rotterdam, Netherlands 1994.

* Computer printouts of specific sections can be made on request. Printouts can be sent by mail, fax or E-mail.

* The entire Catalogue is also available on computer file and can be sent on floppy disks or by E-mail. The file is free available on Erasmus University's anonymous FTP-server. FTP-address: ftp.eur.nl directory: pub/database.happiness filename: correlat.zip Instructions for downloading: see appendix.

\section{CATALOGUE OF HAPPINESS IN NATIONS}

\section{Scope:}

* Distributions of happiness in nations, as observed in representative samples of the adult population.

* Only findings based on survey questions that validly tap happiness in the sense of an individual's 'overall appreciation of his own life-as-a-whole'. 
Coverage at 1-1-1994:

* 689 distributions in 56 countries between 1945-1992.

* Time series for 15 countries of ten years and more.

* Mainly first world countries, but also data from some third and second world nations.

* Fairly complete up to 1990.

\section{Contents:}

* Happiness indicator: full description.

* Statistics: frequency distribution original means and standardized means (scale 0-10).

* Number of respondents, non-response.

* Bibliographics: author, title, year of publication, page reference.

* Survey name: name of survey program or institute.

\section{Availability: ${ }^{2}$}

* Available as a book: 'Happiness in Nations', 365 pages. Published by RISBO, Series: Studies in Social and Cultural Transformation nr. 2, Erasmus University Rotterdam, Netherlands, ISBN 90 $72597-46,1993$.

* Also available on computer file, either by E-mail or on floppy disk. The file is free available on Erasmus University's anonymous FTPserver. FTP-address: ftp.eur.nl directory: pub/database.happiness filename: nations.zip Instructions for downloading: see appendix.

\section{DIRECTORY OF HARPINESS INVESTIGATORS}

Scope:

* Scientists who have published on the subject of the subjective appreciation of life (broader than happiness in the strict sense). Includes most authors of works in the 'Bibliography of Happiness'.

* Research groups that focus on the quality-of-life. 
Coverage at 1-1-1993:

* 2608 names and addresses.

* Mainly investigators who published after 1975.

* Fairly complete up to 1990.

Contents:

* Name

* Institution

* Address

* Year of publications on happiness

Availability: ${ }^{2}$

* Available on computer file by E-mail or on floppy disk.

* Available on paper by mail or fax.

* To be used for scientific purposes only.

CALL FOR DATA

This database is not a one-time compilation, but is a continuously replenished collection. Every year computer files are updated, and every ten years new books are published. The next book publications are scheduled for 2003.

Investigators on happiness are invited to send a copy of their reports to the address below. Keeping this database up to data is so much easier when everybody gives a hand.

Do not confine to authorized publications in books and journal articles. Papers, internal research reports and mere data-files are also welcome. As there are distortions in the publication process (findings deemed unimpressive have, for instance, less chance of being published) the World Database deliberately includes grey publications and plain data as well. 
Colleagues who have a good overview on research in this field in their country are invited to act as a national correspondent for the World Database of Happiness. Please contact Ruut Veenhoven.

\section{Send data to:}

World Database of Happiness

Ruut Veenhoven

Erasmus University Rotterdam, Faculty of Social Sciences, Department of Sociology.

Post Office Box 1738, 3000 DR, Rotterdam, Netherlands

Fax: (0)104525870, Tel: (0)104082102,

E-mail: veenhoven@soc.fsw.eur.nl

NOTES

${ }^{1}$ This project is part of a research program at Erasmus University on 'Social-Cultural Transformations and Policy'.

2 Order-address for books or fles: World Database of Happiness, Ruut Veenhoven, Erasmus University, Faculty of Social Sciences, POB 1738, 3000 DR Rotterdam, Netherlands. Tel: 104082102, Fax: 104525870, E-mail: veenhoven@soc.fsw.eur.n1

\section{APPENDIX}

How to get the database-files on ftp

The World Database of Happiness is free available on Erasmus University's anonymous FTP server, with exception of the Directory of Happiness Investigators. Through Intemet you can load files on your Personal Computer.

* FTP address:ftp.eur.nI

Directory: pub/database.happines

Filenames: info.txt Information-file

DOS text, 10 pages

$0,003 \mathrm{Mb}$

biblio.zip Menu driven database

$0,8 \mathrm{Mb}$ compressed, 2,5 $\mathrm{Mb}$ uncompressed 


\author{
nations.zip Catalogue of Happiness in Nations \\ WP5. 1 text, 1 text-file, 3 table-files, 300 pages \\ $0,5 \mathrm{Mb}$ compressed, 1,9 Mb uncompressed \\ correlat.zip Catalogue of Happiness in Nations \\ Menu driven database \\ 2,5 $\mathrm{Mb}$ compressed, $17 \mathrm{Mb}$ uncompressed
}

The files with extension 'zip' are compressed. They must be de-compressed after transfer. Instruction for decompressing below.

\title{
Instructions for downloading files:
}

* Make sure you have sufficient capacity on your hard disk

* Connect to Intemet. (Ask your administrator for local procedure)

* Connect to Erasmus University's anonymous ftp-server: ftp.eur.nl

* When asked for user-name, type: anonymous

* When asked for password, give your E-mail address (or any other word you wish)

* Go to directory pub/database.happiness with the command: cd pub/database.happiness

* Ask an overview of the files in this directory, with the command: dis or Is

* Set your transfer-mode to 'binary', with the command: binary (ftp $>$ binary)

* Load the file you want, with the command: get (file name) for example: get biblio.zip

* Cut off connection, with the command: quit

* Make a directory on your hard disk.

For example: md C:BIBLIO for the bibliography of happiness.

* Copy the zipfile to this directory. For example: copy biblio.zip C:BIBLIO

* Go to this directory. For example: cd $\backslash$ BIBLIO

* Decompress the zip-files with the program 'pkunzip'. This program is available on many ftp.servers in the world. The command is:

pkunzip -d (filename). For example: pkunzip -d biblio.zip. 
Reading the Information file (info.txt)

* The Information file (index) can be read directly.

The name of the DOSfile is info.txt

\section{Installing the Bibliography of Happiness (biblio.zip)}

* Make a directory. For example: md c: BIBLIO

* Copy zipfile to this directory and unzip (see above).

* You will find now the following three files in this directory:

- biblio: database program and data;

- biblio1: WordPerfect 5.1 file, source description;

- biblio2: WordPerfect 5.1 file, subject index.

The database 'biblio' can be activated with the command biblio (C:BIBLLO biblio) A menu will appear.

The WordPerfect files are prepared for printing on a HP LaserJet printer. Font: Times Roman.

\section{Installing the Catalogue of Correlates (correl.zip)}

* The 'Catalogue of Correlates' (file 'correlat.zip') consists of two text files and various files that constitute a database.

- correl1.txt: Introductory text. Read with Wordperfect 5.1

- correl2,txt: Subject classification. Read with Wordperfect 5.1

- correlat Database-files.

* Make a directory for these files. For example: md C:ICORRELAT

* Copy zipfile to this directory and unzip

Now the directory will contain the following files:

CORREL1.TXT

CORREL2.TXT

CORRELATEXXE

CONFIG.MEM

SETUP.EXE

A subdirectory DATA is created containing the following datafiles:

SOURC.DBF

SOURC.DBT

INDIC.DBF

INDIC.DBT

CORREL.DBF

CORREL.DBT

ASS_MEAS.DBF

ASS_MEAS.DBT 
SOURC.NTX

SOUCORAU.NTX

INDIC.NTX

CORREL.NTX

CORSOUR.TNX

ASS_MEAS.NTX

* The database must be configured before use by means of the program 'setup'.

* Start setup with the command: setup

Strike any key and the following screen will appear:

CORRELATES CATALOGUE - SETUP PROGRAM

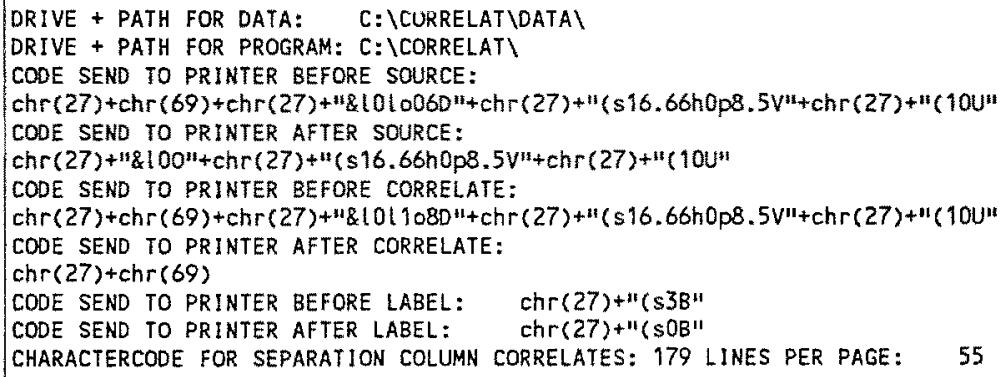

* Check the specification for the drive and path of the program and the data. The Catalogue will not run if this is not correct! Change on the setup-screen if necessary. For example: if you have loaded the program on drive $\mathrm{D}$ : of your computer you must change $\mathrm{C}$ : to $\mathrm{D}$ :

The specified path must end with the character $\backslash$

for example: \CORRELAT or \CORRELATDATA\

The other entries are only used while printing. The code has to be a valid DBase expression. For example: The code for reset on a laser-printer (ESC E) must be specified as: $\operatorname{chr}(27)+$ ' $\mathrm{E}$ '

The default entries, shown above, are the best settings for a Hewlett Packard Laserjet II or compatible printer. Change the codes if necessary.

* When you have entered all the information a menu will appear.

Select 'save'.

You can now activate the 'Catalogue of Happiness Correlates with the command: correlat

* A menu will appear. 


\section{Installing the Catalogue of Happiness in Nations (nations.zip)}

* Make a directory. For example: md C:WATIONS

* Copy zipfile to this directory and unzip (see foregoing page) You will now find four tex files in this directory

- nations1.txt: Text about measuring livability of nations by happiness.

- nations2.txt: Tables on happiness in representative nation samples.

- nations3.txt: Tables on happiness in social categories in nations.

- nations4.txt: Tables on available data by nation.

* These files can be read and printed by means of WordPerfect 5.1 .

Together the files contain some 150 pages text and about 150 pages tables.

Contents are on pages $3-7$ of file nations 1.txt.

The documents are prepared for printing on a HP LaserJet Printer.

Font: Times Roman.

In case of transport problem, contact the network administrator of the Erasmus University, Department of Social Sciences: E-mail: Bouwman@soa.fsw.eur.nl

\section{REFERENCES}

Harding, S.: 1985, "Values and the nature of psychological well-being", in M. Abrams, D. Gerard and N. Timms (eds.) Values and Social Change in Britain (McMillan, London, UK).

Veenhoven, R.: 1984a, Conditions of Happiness (Reidel (Kluwer), Dordrecht, Netherlands).

Veenhoven, R.: 1984b, Databook of Happiness (Reidel, Dordrecht, Netheriands).

Veenhoven, R. (ed.): 1989, How Harmful is Happiness? Consequences of Enjoying Life or Not (Universitaire Pers Rotterdam, The Hague, Netherlands).

Veenhoven, R. 1993, 'Bibliography of happiness, 2472 contemporary studies on subjective appreciation of life', RISBO, series Studies in Social and Cultural Transformation nr. 1, Erasmus University Rotterdam, Netherlands.

Veenhoven, R. 1993, 'Happiness in nations, subjective appreciation of life in 56 nations 1946-1992', RISBO, series Studies in Social and Cultural Transformation nr 2, Erasmus University Rotterdam, Netherlands.

Veenhoven, R. 1994 (in press), 'Correlates of happiness', RISBO, series Studies in Social and Cultural Transformation nr. 3, Erasmus University Rotterdam, Netherlands.

Erasmus University Rotterdam, 3000 DR Rotterdam,

The Netherlands 